\title{
КОНСТИТУЦИОНАЛЬНЫЕ ОСОБЕННОСТИ И ИХ ВЛИЯНИЕ НА ТЕЧЕНИЕ ПРЕМЕНОПАУЗЫ У ЖЕНЩИН
}

\author{
Умарходжаева 3.А., Хайдарова Ф.А.
}

Республиканский специализированный научно-практический медицинский центр Эндокринологии, Ташкент, узбекистан

Изучая литературные данные последних лет, обращает на себя внимание тот факт, что вопросы диагностики и лечения патологических состояний, осложняющих естественное течение предменопазуального периода у женщин, продолжают оставаться в центре внимания не только практических врачей, но и государственных органов здравоохранения.

ЦЕЛЬ: изучить роль различной степени ожирения на течение менопаузы.

МАТЕРИАЛЫ И МЕТОДЫ: в исследовании приняли участие 278 женщин в менопаузальном периоде в возрасте от 40 до 46 лет, из них основную группу (ОГ) составили 218 женщин с избыточной массой тела и ожирением различной степени. В контрольную группу (КГ) вошли 60 женщин с нормальной массой тела и окружностью талии $80 \mathrm{~cm}$.

Всем женщинам проводились антропометрические исследования, изучались данные анамнеза, проводился общий и гинекологический осмотр, тяжесть климактерического синдрома оценивали по шкале Грина.

PEЗУЛЬтАТЫ: в результате проведенных исследований нами установлено, что избыточная масса тела (ИМТ - 25,0-29,9 кг/м²) отмечалась у 62 женщин (28,4\%) из 218 обследованных в основной группе в остальных случаях зафиксировано ожирение различной степени тяжести (ИМТ - 30,0-41,2 кг/м²).

$72,0 \%$ женщин с избыточной массой тела увеличение ИМТ отмечали после 36 лет, т.е. в начале позднего репродуктивного периода, тогда как женщины с ожирением различной степени тяжести после 40 лет. В КГ $33 \%$ женщин из КГ отмечали повышение веса после 36 лет, хотя эти показатели не выходили за пределы нормы.

Женщины с избыточной массой тела и ожирением имели высокую коморбидность, так у $36 \%$ женщин из ОГ регистрировалась артериальная гипертензия, у 22\% - ишемическая болезнь сердца, у 10\% - хроническая венозная недостаточность, аритмии отмечали $10 \%$ женщин. Особенно хочется выделить частоту заболеваний ЖКТ у женщин ОГ, из них 42\% - желчнокаменная болезнь, 62,4\% - хронический гастрит, $18,3 \%$ - хронический колит, $6 \%$ - язвенная болезнь и у $28,4 \%$ - хронический панкреатит. Частота встречаемости генекологической патологии также зависела от показателей ИМТ, так у женщин с избыточной массой тела в 58,4\% случаях отмечались миома матки, аденомиоз и др., тогда как в КГ этот процент составил $13,8 \%$.

Спектр клинических симптомов у женщин с избыточной массой тела, ожирением и нормальной массой тела различается, у первых и вторых преобладают головные боли (у 95,0\%), возбудимость (у 72,5\%), нарушение сна (у 67,5\%), мышечные и суставные боли (у 62,5\%), сексуальная дисфункция (у 52,5\%). Климактерический синдром у пациенток ожирением протекает в более тяжелой форме, и чаще манифестирует такими климактерическими симптомами, как сердцебиение и тахикардия, возбудимость, головокружение, мышечные и суставные боли, приливы, сексуальная дисфункция.

Выводы: таким образом, период менопаузы связан с повышенной распространенностью избыточной массой тела. Повышенное отложение центрального жира, снижение уровня отложений периферического жира и накопление эктопического жира способствуют кардиометаболическим нарушениям, что приводит к увеличению распространенности метаболического синдрома после менопаузы. 